\title{
Anterior Segment Complications in Ocular Contusion
}

\section{Penpe Gul Firat*, Selim Doganay, Tongabay Cumurcu, Soner Demirel and Derya Kutukde}

Department of Ophthalmology, Turgut Ozal Medical Center, Inonu University, Malatya, Turkey

\begin{abstract}
Purpose: To evaluate visual outcomes and anterior segment complications in patients with ocular contusion trauma.

Methods: All cases of ocular trauma were reviewed retrospectively from January 2008 to December 2010 via a computerized database; forty-six cases of ocular contusion were identified. Patients' demographic features, initial and final clinical findings and also initial and final best corrected visual acuities (BCVA) of logMar were recorded. Patients were grouped according to age; 18 years or younger were grouped in group 1, and older than 18 years group 2. Initial and final anterior segment findings affecting the initial and final BCVA were investigated. Also anterior segment findings and initial and final BCVA were compared among the groups.
\end{abstract}

Results: In group 1 there were $19(63.3 \%)$ males and 11 (26.7\%) females; group 2 was comprised of $12(75 \%)$ male and four $(25 \%)$ female subjects. There was no statistically significant difference in initial BCVA between the groups ( $p>0.05$ ), final BCVA difference in group 1 was found to be statistically significant $(p<0.05)$. Cataract and angle recession were found to be more prevalent in group $2(p<0.05)$. Initial anterior segment findings contributed to $61.4 \%$ of initial BCVA, whereas final anterior segment findings explained $57.4 \%$ of final BCVA.

Conclusion: Exact examination and management at the proper time of findings are essential for successful treatment and an improved visual prognosis for ocular contusion.

Keywords: Ocular contusion; Traumatic cataract; Hyphema; Corneal scar; Secondary glaucoma

\section{Introduction}

Ocular traumas are the leading cause of preventable vision loss in children and adults. The incidence of eye injuries varies between countries. In a previous study that was made by McGwin et al. in 2005, it was found that the number of ocular injuries in United States annually is approximately 2 million, with 40 thousand resulting in permanent vision loss [1]. Many studies have investigated open globe injuries that can be managed primarily through surgery $[2,5]$. Management of blunt trauma is sometimes more challenging, as unforeseen complications can occur. Usually blunt ocular trauma is managed on a case by case basis. Blunt ocular trauma or ocular contusions cause an antero-posterior compression of the globe and elongation of the equatorial area. Both anterior and posterior segment structures may be influenced by this rapid deformation of ocular tissues. Cornea, iris, lens, and zonule are the most affected tissues from trauma as they are vulnerable to acute deformation. The restoration process of these tissues frequently results in a nonfunctional configuration [6]. Previous studies have discussed specific complications such as traumatic hyphema [7], cataract [8], glaucoma [9] and corneal endothelial changes [10]. A few studies have discussed all anterior complications of ocular contusion.

The aim of this study is to investigate anterior segment complications, outcomes and factors affecting the prognosis of ocular contusion.

\section{Materials and Methods}

All cases of ocular trauma were reviewed retrospectively from January 2008 to December 2010 via a computerized database. 152 hospitalized injured eyes were reviewed, of which 46 (30.2\%) ocular contusions were available for review. The project was approved by institutional ethics committee. Records were reviewed to determine patients' age, sex, type of trauma, also initial clinical findings including best corrected visual acuity (BCVA), as logMar intraocular pressure (IOP), anterior segment damages such as: corneal injury, hyphema, traumatic cataract, and iris injuries. Final BCVA and clinical findings were also recorded. In three patients BCVA could not be evaluated due to their age. Patients were grouped according to their ages; 18 years or younger were grouped in group 1 and older than 18 years were grouped in group 2. Groups 1 and 2 were compared for initial and final clinical findings and initial and final BCVA.

The following clinical grading system for traumatic hyphemas was utilized: Grade 1 for layered blood occupying less than one third of the anterior chamber, grade 2 for blood filling one third to one half of the anterior chamber, grade 3 for layered blood filling one half to less than total of the anterior chamber and grade 4 for total clotted blood, often referred to as blackball or 8-ball hyphema [11].

Data analysis was conducted using SPSS version 15.0 for Windows (Cary, NC). Results were statistically analyzed using Wilcoxan test, and a correlation between age and clinical findings were analyzed using Fisher's exact test. We used factor analysis to evaluate the correlation between clinical findings and BCVA. $\mathrm{P}$ values less than 0.05 were considered statistically significant.

\section{Results}

There were 30 subjects in group 1 and 16 subjects in group 2. The study comprised 19 (63.3\%) males and $11(36.7 \%)$ females in group 1

*Corresponding author: Penpe Gul Firat, MD, Assistant Professor, Department of Ophthalmology, Turgut Ozal Medical Center, Inonu University, Malatya, Turkey, E-mail: pembeglbozgl@yahoo.com

Received November 14, 2011; Accepted December 09, 2011; Published December 12, 2011

Citation: Firat PG, Doganay S, Cumurcu T, Demirel S, Kutukde D (2011) Anterior Segment Complications in Ocular Contusion. J Trauma Treat 1:101. doi:10.4172/2167-1222.1000101

Copyright: (c) 2011 Firat PG, et al. This is an open-access article distributed under the terms of the Creative Commons Attribution License, which permits unrestricted use, distribution, and reproduction in any medium, provided the original author and source are credited. 
and $12(75 \%)$ males and four females $(25 \%)$ in group 2 . The mean age was 10.3 \pm 4.3 years in group 1 and $52.1 \pm 18.04$ years in group 2 .

The type of trauma was classified into 4 categories: sports related in 22 eyes (47.8\%), home accidents in 15 eyes (32.6\%), industrial accidents in seven eyes (15.2\%) and assault related in two eyes (4.3\%).

Initial and final clinical findings (Table 1) and initial and final BCVA values (Table 2) were compared among the groups.

In our study nine eyes (19.5\%) required surgical intervention. We performed anterior chamber irrigation to two eyes, phacoemulsification to three eyes, pars plana vitrectomy (PPV) to one eye and combine PPV and lensectomy to three eyes.

\section{Discussion}

Hyphema, glaucoma, angle recession, iris deformities, cataract, and lens luxation or subluxation are reported complications of ocular contusion [12].

In most population-based studies to date, there is a strong preponderance of ocular injuries affecting males [13,14]. In our study, the majority of all injuries occurred in men with an incidence of $63.3 \%$ in group 1, and $75 \%$ in group 2. Although males were more affected by trauma there was no statistically significant difference between the males and females according to the initial and final clinical findings $(\mathrm{p}>0.05)$.

Previous studies have reported that factors such as patient age, existing cataract and red reflex negatively affect final visual acuity.
In this current study we investigated the correlation between initial clinical findings and initial BCVA. When we investigated the relation between initial clinical findings (hyphema, corneal abrasion, corneal edema, higher IOP, and cataract at presentation), and initial BCVA we found that these initial clinical findings contributed to $61.4 \%$ of initial BCVA. $61.4 \%$ of vision loss at presentation after an ocular trauma can be explained by anterior segment components. The remaining percentage can be explained by the other factors such as posterior segment findings, age, etc. We also investigated the correlation between final clinical findings including angle recession, iridodialysis, corneal scar, secondary glaucoma, cataract, and final BCVA. We found out that $57.4 \%$ percent of final BCVA can be explained by these final anterior segment findings.

The prognosis of corneal and conjunctival lesions is usually favorable, with full recovery of vision if managed promptly. Deep abrasions involving the corneal stromal layer in the central visual axis do heal, however injuries related to these abrasions leave a scar. In such instances, visual acuity may be permanently lost. Also long corneal edema may result in a permanent corneal scar [6]. In several studies corneal damage percentages were given as $11.8 \%$ [1], 28\% [2] and 79\% [3]. In these studies, corneal injuries were the second or third common finding in ocular contusions. Corneal injuries were the second common presentation findings in our study among the groups. Three eyes with corneal injuries healed with scar formation one eye $(3.3 \%)$ in group 1 , and two eyes $(12.5 \%)$ in group 2.

The iris has no protection in the event of trauma. Traumatic

\begin{tabular}{|c|c|c|c|}
\hline & $\begin{array}{c}\text { Group } 1 \\
n(\%)\end{array}$ & $\begin{array}{c}\text { Group } 2 \\
n(\%)\end{array}$ & $p$ value \\
\hline \multicolumn{4}{|c|}{ Initial Anterior Segment Findings } \\
\hline Corneal Abrasion & $12(40 \%)$ & $9(56.2 \%)$ & 0.292 \\
\hline Corneal Edema & $10(33.3 \%)$ & $3(18.7 \%)$ & 0.245 \\
\hline Hyphema & $28(93.3 \%)$ & $12(75 \%)$ & 0.163 \\
\hline Cataract at presentation & 0 & $2(12.5 \%)$ & $0.048^{*}$ \\
\hline $\mathrm{IOP} \geq 21 \mathrm{mmHg}$ & $4(13.3 \%)$ & $4(25 \%)$ & 0.421 \\
\hline \multicolumn{4}{|l|}{ Final Anterior Segment Findings } \\
\hline Angle Recession & $8(26.7 \%)$ & $10(62.5 \%)$ & $0.018^{*}$ \\
\hline Iridodyalisis & $6(20 \%)$ & $1(6.3 \%)$ & 0.126 \\
\hline Rehemorrage & $4(13.3 \%)$ & 0 & 0.168 \\
\hline Corneal Scar & $1(3.3 \%)$ & $2(12.5 \%)$ & 0.274 \\
\hline Cataract & 0 & $4(25 \%)$ & $0.004^{*}$ \\
\hline Seconder Glaucoma & $3(10 \%)$ & $3(18.8 \%)$ & 0.342 \\
\hline
\end{tabular}

Group 1: Patients younger than 18 years old, Groups 2: Patients older than 18 years old, $\mathrm{n}$ : Number

*: p<0.05, IOP: Intraocular Pressure

Table 1: Clinical Anterior Segment Findings.

\begin{tabular}{|l|c|c|}
\hline & $\begin{array}{c}\text { Group 1 } \\
\mathbf{n}(\%)\end{array}$ & $\begin{array}{c}\text { Group 2 } \\
\mathbf{n}(\%)\end{array}$ \\
\hline Initial BCVA & & 0 \\
\hline$\geq 0.3$ or better & $2(7.4 \%)$ & $1(6.2 \%)$ \\
\hline $0.4-1$ & $6(22.2 \%)$ & $15(93.7 \%)$ \\
\hline$\leq 1.1$ & $19(70.3 \%)$ & 0.085 \\
\hline Final BCVA & $15(55.5 \%)$ & $5(31.2 \%)$ \\
\hline 0,1 or better & $8(29.6 \%)$ & $5(31.2 \%)$ \\
\hline $0,2-0,3$ & $2(7.4 \%)$ & $7(43.7 \%)$ \\
\hline $0,4-1$ & $2(7.4 \%)$ & $0.0001^{*}$ \\
\hline 1,1 or worse & \\
\hline
\end{tabular}

BCVA: Best Corrected Visual Acuity, Group 1: Patients younger than 18 years old, Groups 2: Patients older than 18 years old, *: p<0.05, n: Number

Table 2: Best Corrected Visual Acuities (LogMar) of Groups. 
mydriasis, sphincter tear, and iridodialysis are the hallmarks of ocular trauma. In our study, iris damages were in nine eyes (30\%) in group 1 , and four eyes $(25 \%)$ in group 2 . Traumatic mydriasis persisted in two eyes in group 2 (12.5\%) which were also followed up for secondary glaucoma.

Angle recession, with or without glaucoma, is a common consequence of blunt ocular trauma characterized by a variable degree of cleavage between the circular and the longitudinal fibers of the ciliary muscle. The reported frequency of angle recession as a complication of blunt trauma is $20-94 \%$ [16,17]. In the follow-up visits angle recession was observed in eight eyes $(26.7 \%)$ in group 1 and in ten eyes $(62.5$ $\%)$ in group 2 . There was a statistically significant difference among the groups for angle recession $(\mathrm{p}<0.05)$. Older patients tend to have more angle recession than younger patients. This can be explained with by an age relation to iris atrophy. Herschler reported that the angle configuration changes after one week, making angle recession more difficult to determine [18]. Angle-recession glaucoma is a relatively infrequent occurrence. In patients with known angle recession, $0-20 \%$ subsequently develops glaucoma [17]. The onset of glaucoma is varies greatly, ranging from immediately after trauma to months or even many years later [17]. In our study angle recession glaucoma developed in three eyes (10\%) in group 1, and in one eye (6.3\%) in group 2.

Papaconstantinou et al. reported that of the all hyphemas, 58\% are grade $1,20 \%$ grade $2,14 \%$ grade 3 , and $8 \%$ are total hyphemas [19]. Hyphema is the most common finding in our study. $93.3 \%$ of all ocular contusion in group 1 and $75 \%$ in group 2 were referred with hyphema. We performed anterior segment irrigation for two patients in group 1 with total hyphema due to high IOP more than five days. Although five patients had total hyphema, none of them had corneal blood staining. Another serious complication associated with hyphema is glaucoma. Increased IOP can cause other serious complications, such as corneal staining and optic nerve atrophy [20]. In our study, three eyes in group 1, and one eye in group 2 experienced secondary glaucoma after hyphema resolved. Secondary bleeding into the anterior chamber is another complication of hyphema. It usually occurs after 3-5 days because of blood clot dissolution and contraction of traumatized vessels [21]. Secondary hemorrhaging occurs in approximately $25 \%$ of all patients with hyphema. The incidence of secondary hemorrhage is higher in hyphemas classified as Grades 2 and 3 [22]. Rehemorrhage occurred in four eyes (14.2\%) in group 1 with grade 1 hyphemas in our series. A large proportion (33\%) of patients younger than six years had secondary hemorrhages; the likelihood of secondary hemorrhages decreases with age [23]. In contrast with the literature, grades of hyphema and patients age in our study were not correlated with rehemorrhage [23]. All rehemorrhaging in our patients occurred with grade 1 hypemas and aged between 10 and 18 years but there was no statistically significant difference among the groups $(p>0.05)$. These patients were not compliant, failing to adhere to physician instructions of wearing an eye patch and bed rest.

Lens dislocation and subluxation are commonly found in conjunction with traumatic cataracts. Traumatic cataracts can present as acute, subacute, or a late onset complication of ocular trauma. We classified traumatic cataract in our study as lens luxation to vitreous, acute mature traumatic cataract and subacute traumatic cataract. Lens dislocation to vitreous was seen in three eyes (6.5\%) in group 2. With a mean age of 63 years (range 55-73), all three patients were in group
2, who may have previously had a senile cataract or zonular instability, predisposing these patients for drop lens. We performed combine pars plana vitrectomy and lensectomy for these patients. Ages of the two patients having acute phacomorphic glaucoma due to mature cataract were 61 years and 69 years. All cases of traumatic cataract were in group 2, and it was statistically significant (Pearson chi-square test, $\mathrm{p}<0.05$ ). After decreasing IOP to acceptable levels for surgery, phacoemulsification was performed, but despite cataract removal glaucoma persisted. In four eyes cataract developed in the follow-up visits. Coup, contrecoup, and equatorial expansion are the factors attributed to traumatic cataract formation after ocular contusion [8].

Post-traumatic glaucoma incidences were $10 \%$ in group 1, and $18.8 \%$ in group 2 in our study. Two peak of glaucoma development occurred; less than 1 year and at least 10 years after trauma. Girkin et al. found an incidence of $3.3 \%$ after ocular contusion during 6 month follow-up. According to this study, angle recession, lens injury, hyphema, advancing age, and poor visual acuity were factors independently associated with traumatic glaucoma [9].

Despite poor initial vision many eyes achieve good final visual acuities. Only two eyes (7.4\%) in group 1 and seven eyes (43.7\%) in group 2 retained a final BCVA of LogMar 1.1 or worse, the equivalent to legal blindness. Nevertheless, there was no statistically significant difference in initial BCVA between the groups ( $>00.05)$, final BCVA was statistically improved in group $1(\mathrm{p}<0.05)$.

\section{Conclusion}

Traumatic cataract, corneal opacities and secondary glaucoma are the anterior segment complications that result in poor visual acuity after ocular contusion. Exact examination and management at the proper time of findings are essential for successful treatment and an improved visual prognosis for ocular contusion.

\section{References}

1. McGwin G Jr, Xie A, Owsley C (2005) Rate of eye injury in the United States Arch Ophthalmol 123: 970-976.

2. Smith AR, O'Hagan SB, Gole GA (2006) Epidemiology of open- and closedglobe trauma presenting to Cairns Base Hospital, Queensland. Clin Experiment Ophthalmol 34: 252-259.

3. Andreoli MT, Andreoli CM (2011) Geriatric traumatic open globe injuries Ophthalmol 118: 156-159.

4. Rahman I, Maino A, Devadason D, Leatherbarrow B (2006) Open globe injuries: factors predictive of poor outcome. Eye 20: 1336-1341.

5. Gupta A, Rahman I, Leatherbarrow B (2009) Open globe injuries in children factors predictive of a poor final visual acuity. Eye 23: 621-625

6. Canavan YM, Archer DB (1982) Anterior segment consequences of blunt ocular injury. Br J Ophthalmol 66: 549-555.

7. Mowatt L, Chambers C (2010) Ocular morbidity of traumatic hyphema in a Jamaican hospital. Eur J Ophthalmol 20: 584-589.

8. Kuhn F (2010) Traumatic cataract: what, when, how. Graefes Arch Clin Exp Ophthalmol 248: 1221-1223.

9. Girkin CA, McGwin G, Long C, Morris R, Kuhn F (2005) Glaucoma after ocular contusion: a cohort study of the United States eye injury registry. J Glaucoma 14: $470-473$.

10. Pong J, Lai J (2009) Effect on corneal endothelial cell count of traumatic microhyphaema and hyphaema. Acta Ophthalmol 87: 559-561.

11. Edwards WC, Layden WE (1973) Traumatic hyphema. A report of 184 consecutive cases. Am J Ophthalmol 75: 110-116. 
Citation: Firat PG, Doganay S, Cumurcu T, Demirel S, Kutukde D (2011) Anterior Segment Complications in Ocular Contusion. J Trauma Treat 1:101. doi:10.4172/2167-1222.1000101

Page 4 of 7

12. Taban M, Taban M, Sears JE (2008) Ocular findings following trauma from paintball sports. Eye 22: 930-934.

13. Wong TY, Tielsch JM (1999) A population based study on the incidence of severe ocular trauma in Singapore. Am J Ophthalmol 128:345-351.

14. Klopfer J, Tielsch JM, Vitale S, See LC, Canner JK (1992) Ocular trauma in the United States. Eye injuries resulting in hospitalization, 1984 through 1987. Arch Ophthalmol 110: 838-842.

15. Entezari M, Rabei HM, Badalabadi MM, Mohebbi M (2006) Visual outcome and ocular survival in open-globe injuries. Injury $37:$ 633-637.

16. Wolff SM, Zimmerman LE (1962) Chronic secondary glaucoma. Association with retro displacement of iris root and deepening of the anterior chamber angle secondary to contusion. Am J Ophthalmol 84: 547-563.

17. Sihota R, Kumar S, Gupta V, Dada T, Kashyap S, et al. (2008) Early predictors of traumatic glaucoma after closed globe injury: trabecular pigmentation, widened angle recess, and higher baseline intraocular pressure. Arch Ophthalmol 126: 921-926.
18. Herschler J (1977) Trabecular damage due to blunt anterior segment injury and its relationship to traumatic glaucoma. Trans Sect Ophthalmol Am Acad Ophthalmol Otolaryngol 83: 239-248.

19. Papaconstantinou D, Georgalas I, Kourtis N, Karmiris E, Koutsandrea C, et al (2009) Contemporary aspects in the prognosis of traumatic hyphemas. Clin Ophthalmol 3: 287-290.

20. Hitchings R (2001) Traumatic glaucoma. J Glaucoma 10: 436-439.

21. Witteman GJ, Brubaker SJ, Johnson M, Marks RG (1985) The incidence of rebleeding in traumatic hyphema. Ann Ophthalmol 17: 525-526.

22. Crouch ER Jr, Frenkel M (1976) Aminocaproic acid in the treatment of traumatic hyphema. Am J Ophthalmol 81: 355-360.

23. Read JE, Goldberg MF (1974) Blunt ocular trauma and hyphema. Int Ophthalmol Clin 14: 57-97. 